\title{
Catching crumbs from the table
}

\section{In the face of metahuman science, humans have become metascientists.}

\section{Ted Chiang}

$t$ has been 25 years since a report of original research was last submitted to our editors for publication, making this an appropriate time to revisit the question that was so widely debated then: what is the role of human scientists in an age when the frontiers of scientific inquiry have moved beyond the comprehensibility of humans?

No doubt many of our subscribers remember reading papers whose authors were the first individuals ever to obtain the results they described. But as metahumans began to dominate experimental research, they increasingly made their findings available only via DNT (digital neural transfer), leaving journals to publish second-hand accounts translated into human language.

Without DNT, humans could not fully grasp earlier developments nor effectively utilize the new tools needed to conduct research, while metahumans continued to improve DNT and rely on it even more. Journals for human audiences were reduced to vehicles of popularization, and poor ones at that, as even the most brilliant humans found themselves puzzled by translations of the latest findings.

No one denies the many benefits of metahuman science, but one of its costs to human researchers was the realization that they would probably never make an original contribution to science again. Some left the field altogether, but those who stayed shifted their attentions away from original research and toward hermeneutics: interpreting the scientific work of metahumans.

Textual hermeneutics became popular first, since there were already terabytes of metahuman publications whose translations, although cryptic, were presumably not entirely inaccurate. Deciphering these texts bears little resemblance to the task performed by traditional palaeographers, but progress continues: recent experiments have validated the Humphries decipherment of decade-old publications on histocompatibility genetics.

The availability of devices based on metahuman science gave rise to artefact hermeneutics. Scientists began attempting to 'reverse engineer' these artefacts, their goal being not to manufacture competing products, but simply to understand the physical principles underlying their operation. The most common technique is the crystallographic analysis of nanoware appli- ances, which frequently provides us with new insights into mechanosynthesis.

The newest and by far the most speculative mode of inquiry is remote sensing of metahuman research facilities. A recent target of investigation is the ExaCollider recently installed beneath the Gobi Desert, whose puzzling neutrino signature has been the subject of much controversy. (The portable neutrino detector is, of course, another metahuman artefact whose operating principles remain elusive.)

The question is, are these worthwhile undertakings for scientists? Some call them a waste of time, likening them to a Native American research effort into bronze smelting when steel tools of European manufacture are readily available. This comparison might be more apt if humans were in competition with metahumans, but in today's economy of abundance there is no evidence of such competition. In fact, it is important to recognize that - unlike most previous lowtechnology cultures confronted with a hightechnology one - humans are in no danger of assimilation or extinction.

There is still no way to augment a human brain into a metahuman one; the Sugimoto gene therapy must be performed before the embryo begins neurogenesis in order for a brain to be compatible with DNT. This lack of an assimilation mechanism means that human parents of a metahuman child face a difficult choice: to allow their child DNT interaction with metahuman culture, and watch him or her grow incomprehensible to them; or else restrict access to DNT during the child's formative years, which to a metahuman is deprivation like that suffered by Kaspar Hauser. It is not surprising that the percentage of human parents choosing the Sugimoto gene therapy for their children has dropped almost to zero in recent years.

As a result, human culture is likely to survive well into the future, and the scientific tradition is a vital part of that culture. Hermeneutics is a legitimate method of sci-

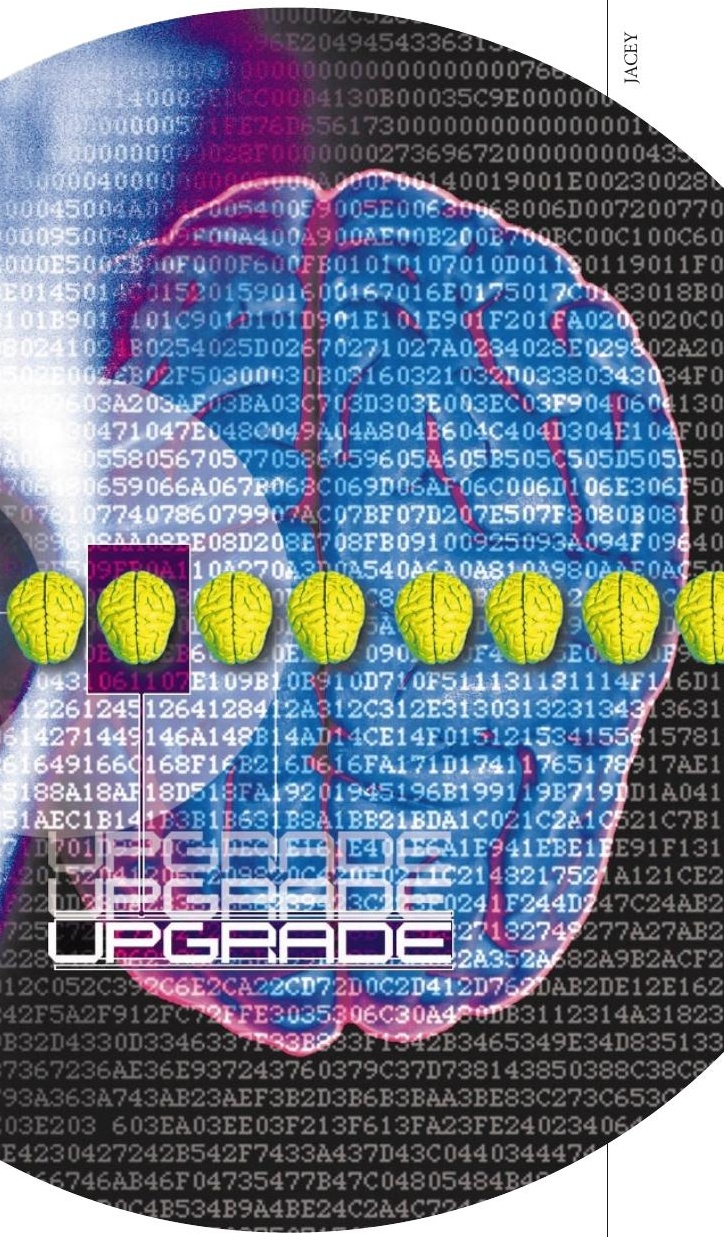

entific inquiry and increases the body of human knowledge just as original research did. Moreover, human researchers may discern applications overlooked by metahumans, whose advantages tend to make them unaware of our concerns.

For example, imagine if research offered hope of a different intelligence-enhancing therapy, one that would allow individuals to gradually 'upgrade' their minds to a level equivalent to that of a metahuman. Such a therapy would offer a bridge across what has become the greatest cultural divide in our species' history, yet it might not even occur to metahumans to explore it; that possibility alone justifies the continuation of human research.

We need not be intimidated by the accomplishments of metahuman science. We should always remember that the technologies that made metahumans possible were originally invented by humans, and they were no smarter than we.

Ted Chiang is an occasional writer of science fiction. His latest story can be found in the anthology Vanishing Acts, published by Tor Books. 